\title{
STRUKTUR RUANG ARTISTIK DALAM NOVEL NEGERI 5 MENARA KARYA AHMAD FUADI
}

\author{
Irma Yuliana Afianti \\ Akademi NU Banat Kudus, Indonesia \\ email: irmayulianaafianti@gmail.com
}

\begin{abstract}
ABSTRAK
Novel Negeri 5 Menara ini memaparkan perjuangan meraih mimpi tanpa mengesampingkan kewajiban sebagai manusia. Struktur ruang artistik menjadi fokus penelitian dengan memunculkan tokoh Alif yang mempertahankan akidah di tengah keberagaman masyarakat yang ada disekelilingnya. Tujuan dari penelitian ini yaitu mendeskripsi dan menjelaskan struktur ruang artistik yang leiputi struktur teks dan struktur sosial yang melatarbelakangi lahirnya karya tersebut. Teori yang digunakan yaitu Stukturalisme Genetik Lucien Goldmann. Pada teknik analisis data digunakan adalah metode dialektik. Penelitian ini dimulai dengan menformulasikan dan menganalisis struktur ruang artistik yang dimulai dari analisis struktur teks kemudian analisis struktur sosialnya. Hasil penelitian menunjukkan bahwa struktur teks novel Negeri 5 Menara meliputi ruang artistik yang terbangun dari beberapa medan semantis berupa elemen-elemen yang berelasi antara satu dengan yang lain dan adanya oposisi berpasangan. Struktur teks yang terakhir yaitu latar, meliputi latar ruang, latar waktu, dan latar sosial. Struktur sosial yang melatarbelakangi lahirnya karya ini memiliki hubungan erat dengan struktur sosial pengarang selama di pesantren, struktur sosial Indonesia pada masa reformasi dan insiden gedung WTC di Washington DC, dan juga kondisi kesastraan islami era tahun $2000 a n$. Berdasarkan penelitian yang telah dilakukan, apa yang diceritakan pengarang dalam Negeri 5 Menara sangat relevan dengan perjalanan hidup pengarang.
\end{abstract}

Kata Kunci: Novel, Negeri 5 Menara, Struktur Ruang Artistik

\begin{abstract}
Novel Negeri 5 Menara described the struggle to achieve dreams without prejudice to the obligation as a human being. The structure of artistic space is the focus of research by bringing up the figure of Alif who maintains the faith in the midst of the diversity of the people around him. The purposes of this study were, describing and explaining the structure of artistic space which include the structure of the text and the social strcture behind the birth of the work. The theory used in this study were the Genetic Structuralism Lucien Goldmann. The data were analyzed by using the dialectic of text method. The results showed that the text structure of the novel Negeri 5 Menara includes artistic space that is built from several semantic fields in the form of elements that are related to one anothe and the presence of paired opposition. The last structure the background, includes the setting space, time setting, and social setting.The social structure that became the background of this work had a close relationship with the author's life during the social structure in his islamic boarding school, the social structure of Indonesia in the reformation period and the WTC incident in Washington DC, and the condition of Islamic literature of the 2000s era. Based on the study conducted, what author told in the Negeri 5 Menara was highly relevant to the author's life
\end{abstract}

Keyword: Novel, Negeri 5 Menara, Structure of Artistic Space 


\section{PENDAHULUAN}

Karya sastra termasuk dalam salah satu wacana yang tidak berbeda dengan wacana-wacana yang lain. Karya sastra hadir dalam dialektika teks dan kontekstualitas, dengan kata lain bahwa karya sastra merupakan representasi ideologi pengarang dalam mempersepsi kelompok sosial masyarakat (subjek kolektif). Itulah sebabnya sastra merupakan refleksi ideologi kelompok kelas sosial Supriyanto [1]. Karya sastra sarat dengan muatan ideologi, tetapi mempunyai ciri khas yang beda dengan wacana-wacana lainnya, yaitu aspek estetika yang dominan. Eksistensi estetika itulah yang menjadikan karya sastra selalu menyampaikan ideologi secara tidak langsung. Artinya, ideologi dalam karya sastra, terutama fiksi, selalu melebur dalam fakta cerita yang dihadirkan. Karya sastra selalu berisi tentang kehidupan yang telah difiksikan pengarang, sehingga membaca karya sastra seperti menikmati petualangan melalui kata-kata.

Tujuan karya sastra adalah sebagai penambah wawasan bagi orang yang membaca karya tersebut. Dengan membaca, penikmat karya sastra diharapkan mampu memahami kondisi sosiokultural masyarakat tertentu. Selain memahami kondisi tersebut, dengan membaca karya sastra masyarakat bisa terhibur, sebagaimana fungsi dari karya sastra yaitu dulce et utile, bukan sekadar hiburan tapi juga memberi manfaat bagi pembaca.

Salah satu karya sastra yang banyak dibaca dari berbagai kalangan masyarakat adalah novel. Novel bercerita tentang kehidupan manusia yang berinteraksi dengan manusia lainnya dan juga lingkungan sekitar. Interaksi tersebut menimbulkan suatu kejadian yang luar biasa melalui tokoh-tokoh dalam cerita sedemikian rupa, sehingga menimbulkan konflik dan pergolakan batin serta benturan-benturan antartokoh.

Selain itu, karya sastra memberikan pesan moral. Salah satu pesan moral itu berwujud religiusitas. Religiusitas adalah sebuah ekspresi spiritual seseorang yang berkaitan dengan sistem keyakinan, nilai, dan hukum yang berlaku. Dengan demikian, religiusitas sangat mempengaruhi perilaku dan tindakan manusia, baik yang dilakukan secara perorangan maupun kelompok. Religiusitas dalam karya sastra sangat diperlukan karena sastra tumbuh dari sesuatu yang bersifat religius. Religiusitas lebih melihat aspek yang ada di dalam lubuk hati, riak getaran hati nurani pribadi, sikap personal. Religiusitas lebih bergerak dalam tata paguyuban (Gemeinschaft) dengan ciri yang lebih intim Mangunwijaya [2].

Pada sepuluh tahun terakhir, bermunculan novel-novel dengan tema religius yang sangat kental. Bermula dari Habiburrahman El Shirazy dengan melahirkan Ayat-Ayat Cinta. Disusul oleh tetralogi Laskar Pelangi karya Andrea Hirata yang bertema perjuangan anak-anak dari pelosok Belitung untuk meraih cita-cita, juga meraih bestseller dan diangkat pula ke layar lebar. Fenomena yang lain adalah novel trilogi karya Ahmad Fuadi yang mengisahkan perjuangan meraih mimpi dengan setting pondok pesantren, yang juga meraih bestseller dan diangkat ke layar lebar. Habiburrahman El Shirazy, Andrea Hirata, maupun Ahmad Fuadi menjawab kerinduan masyarakat Indonesia akan penulis baru yang menghadirkan ide-ide segar, memotivasi, dan menginspirasi.

Negeri 5 Menara merupakan salah satu karya besar yang telah menginspirasi banyak pihak. Bagaimana tokoh utama digambarkan sebagai sosok tokoh hero yang humanis dan religius. Tokoh utama yang pantang menyerah dan gigih untuk mewujukan cita-cita. Selain tokoh yang problematik, karya ini dipilih karena dalam novel ini ditonjolkan mantra-mantra khas yang mampu membangkitkan semangat bagi siapapun yang membaca. Dengan alasan inilah, karya ini menjadi sangat menarik untuk diungkap pandangan dunia pengarangnya. Pandangan dunia humanis religius menjadi sangat dominan dalam Negeri 5 Menara.

Banyak penelitian yang menggunakan novel sebagai objek kajian. Bahkan peneliti asing yang menggunakan novel sebagai objek kajian juga makin merebak akhir-akhir ini. Mengenai penelitian novel yang telah dilakukan oleh peneliti asing dapat diketahui melalui tulisan yang berjudul "History, Culture and Tradition in Helon Habila's Measuring Time" memaparkan tentang perkembangan sastra Nigeria yang begitu pesat [8]. Terutama dalam penulisan novel. Tenshak berusaha mengungkap novel yang ditulis oleh Helon Habilla seorang penulis asli Nigeria yang tulisannya banyak dipengaruhi oleh Neo-Kolonialisme yang ada di Nigeria. 
Pada penelitian lain dengan judul tulisan "Indian Postmodern English Novels: A Diachronic Survey" terungkap bahwa novel-novel yang ada di India masih sangat dipengaruhi oleh Post-Modernisasi [9]. Dengan adanya hal itu, novel yang ada di India menjadi sangat terbatas. Selain itu, Subha juga membahas tentang besarnya pengaruh bahasa Inggris di India. Terbukti bahwa banyak novel-novel yang diterbitkan dalam bahasa Inggris yang beredar di India.

Dalam penelitian "Gender, Power, Politeness and Women in the Arab Society" membahas tentang perempuan yang memiliki cara yang berbeda dari laki-laki yang mencerminkan dan menghasilkan subordinat posisi dalam masyarakat[10]. Argumen ini telah digunakan untuk menegaskan bahwa jenis kelamin perempuan tidak menjadi penghalang dari posisi kekuasaan dan otoritas. Dengan demikian, gender memaksa laki-laki menjadi lebih santun terhadap perempuan meskipun laki-laki dianggap menjadi yang terbaik daripada kaum perempuan. Tapi konsep kesopanan cukup kompleks dan harus dipelajari serta diselidiki dari berbagai perspektif sebagai norma-norma yang mengatur fenomena kesopanan. Seperti kasus perempuan dalam masyarakat Arab. Gender, kekuatan, kesopanan dan peraturan serta norma-norma yang mengatur mereka dalam masyarakat Arab, merupakan cerminan dari karya-karya yang ada dalam masyarakat.

Selain dari penelitian asing, kajian novel juga tak kalah populer di tanah air. Penelitian dengan judul "Novel Ranah 3 Warna Analisis Psikologi dan Nilai Pendidikan" yang menyatakan bahwa plot atau alur novel Ranah 3 Warna secara umum menggunakan plot atau alur majumundur; penokohan yang diciptakan pengarang berhasil menggambarkan secara riil karakter manusia [11]. Perwatakan yang diciptakan pengarang terbagi atas dua sisi watak, yaitu tokoh sederhana dan tokoh bulat atau tokoh kompleks; setting atau latar cerita novel Ranah 3 Warna adalah kota Bayur tepatnya di Meninjau, Gontor (Jawa Timur), Bandung, dan Quebec (Amerika). Sudut pandang novel Ranah 3 Warna menggunakan sudut pandang persona pertama (firt-person) atau gaya "Aku"; dan amanat novel yang banyak memberi motivasi para kaum muda dalam bidang kehidupan khususnya dunia pendidikan.

Selanjutnya penelitian dengan judul "Kajian Intertekstual dan Nilai Pendidikan Novel Sang Pemimpi Karya Andrea Hirata dan Novel Ranah 3 Warna Karya Ahmad Fuadi" dapat diketahui bahwa dalam temuan penelitian tersebut: (1) memiliki unsur pembangun yang padu, dari unsur pembangun yang ditemukan novel Sang Pemimpi terbit terlebih dahulu merupakan hipogram, sedangkan novel Ranah 3 Warna yang terbit sesudahnya disebut sebagai transformasinya; (2) unsur-unsur pembangun kedua novel memiliki persamaan dan perbedaan [12].

Penelitian dengan judul "Aspek Motivasi Pada Novel Negeri 5 Menara Karya Ahmad Fuadi Dan Novel Sepatu Dahlan Karya Khrisna Pabichara: Kajian Intertekstual dan Implementasinya Sebagai Bahan Ajar Sastra Di SMA" berbicara bahwa struktur novel Negeri 5 Menara dan Sepatu Dahlan meliputi, tema, alur, penokohan dan perwatakan, latar, dan sudut pandang pengarang [13]. Dilihat dari strukturnya, kedua novel ini memiliki persamaan dan perbedaan. Persamaan terletak pada aspek: (1) tema, kedua novel ini bertema pendidikan, (2) alur, kedua novel ini beralur campuran; (3) sudut pandang, kedua novel menggunakan sudut pandang orang pertama (first person narator). Perbedaan kedua novel terletak pada aspek: (1) latar; (2) penokohan dan perwatakan. Sementara itu, hubungan intertekstual aspek motivasi kedua novel terdapat kesamaan pada aspek motivasi yaitu pada aspek: (1) adanya hasrat dan keinginan berhasil; (2) adanya dorongan dan kebutuhan dalam belajar; (3) adanya harapan dan cita-cita masa depan; (4) adanya penghargaan dalam belajar; (5) adanya kegiatan yang menarik dalam belajar; (6) adanya lingkungan belajar yang kondusif.

Dari apa yang telah dipaparkan, terdapat relevansi antara penelitian ini dengan penelitian sebelumnya, yaitu sama-sama menjadikan novel sebagai objek kajian. Namun, tetap ada perbedaan yaitu mengaitkan penelitian novel dengan pembelajaran di sekolah. Berdasarkan pemaparan tersebut, maka penting untuk diadakan penelitian guna mengetahui lebih isi Negeri 5 Menara. Berpijak dari apa yang telah dipaparkan, perlu dilakukan penyelidikan yang lebih mendalam, yaitu struktur ruang artistik yang meliputi struktur teks dan struktur sosial yang melatarbelakangi lahirnya karya tersebut. 
Novel adalah proses rekaan yang panjang, yang menyuguhkan tokoh-tokoh dan penampilan serangkaian peristiwa dan latar secara tersusun. Novel jauh lebih panjang jika dibandingkan cerpen sehingga novel dapat mengemukakan sesuatu secara bebas, lebih rinci, lebih mendetail dan menyajikan sesuatu lebih banyak. Novel biasanya mengisahkan kehidupan seorang tokoh dari semenjak kecil hingga dewasa, atau tokoh tersebut telah mengalami perubahan nasib dalam struktur yang cukup panjang. Novel lebih detail dalam menyampaikan cerita untuk menggambarkan realitas yang dijalani oleh tokoh. Hal itu sangat mungkin adanya keluasan cerita yang sering terdeskripsikan dengan bebas.

Novel pun bisa dibedakan dengan roman, novel bersifat realistis, sedang roman cenderung puitis dan epik. Tokoh dalam novel lebih realistis, lebih objektif, ia merupakan tokoh yang memiliki derajat lifelike, sedangkan tokoh dalam roman cenderung subjektif. Hal ini sesuai dengan pendapat Wellek dan Warren [3] bahwa novel lebih menggambarkan tokoh nyata, tokoh yang berangkat dari realitas sosial. Jadi merupakan tokoh yang lebih memiliki derajat lifelike.

Berbeda dengan pandangan Wallek dan Warren, Goldmann sebagaimana dikutip oleh Faruk [4] mengatakan bahwa novel merupakan suatu genre sastra yang bercirikan keterpecahan yang tidak terdamaikan dalam hubungan antara sang hero dengan dunia. Keterpecahan itulah yang menyebabkan dunia dan hero menjadi sama-sama terdegradasi dalam hubungannya dengan nilainilai otentik yang berupa totalitas di atas. Keterpecahan itu yang membuat sang hero menjadi problematik. Goldmann membagi novel menjadi tiga jenis, yaitu novel 'idealisme abstrak', 'romantisme keputusasaan', dan 'pendidikan'.

Lebih lanjut Faruk [4] menjelaskan bahwa novel merupakan wacana yang di dalam dan lewatnya masyarakat mengartikulasikan dunia. Di dalam novel kata-kata disusun sedemikian rupa agar melalui aktivitas pembacaan akan muncul suatu model mengenai suatu dunia sosial, modelmodel personalitas individual, model hubungan antara individu dengan masyarakat, dan lebih penting lagi model signifikansi dari aspek dunia-dunia tersebut.

Berdasarkan pendapat beberapa pendapat di atas, dapat disintesiskan bahwa novel adalah karya sastra fiksi yang menceritakan kehidupan para tokoh dengan segala problematikanya. Novel juga berisi pesan kebajikan dan idealisme hidup lewat tokoh hero yang menjadi dasar untuk menemukan nilai-nilai keotentikan hidup dalam dunia yang terdegradasi. Novel memiliki satuansatuan organisasi cerita yang lebih luas dan mendetail. Novel Negeri 5 Menara merupakan novel bersambung yang menceritakan tokoh hero bernama Alif Fikri.

Teks sastra dianalisis dari sudut intrinsik dan untuk mengmahami relasi ideologis yang ada di dalam teks maupun di luar teks perlu dianalisis struktur ruang artistik Supriyanto [1]. Teks sastra merupakan bangun struktur yang signifikan, yaitu merupakan produk strukturasi yang berlangsung secara terus-menerus dari subjek tertentu terhadap dunia. Pandangan Goldmann mengenai strukturasi dalam teks sastra melahirkan suatu metode dialektik, yang tidak hanya berhubungan dengan subyek sosial juga mempersoalkan koherensi struktural didalamnya Faruk [4] . Metode dialektik bergerak melingkar tidak ada titik mula yang benar-benar valid, secara simultan menautkan bagian-bagian kecil dalam keutuhan, menelusur bagian besar untuk menjelaskan bagian kecil sementara bagian besar tak mungkin di jelaskan tanpa kehadiran bagianbagian kecil. Oleh karenanya metode ini berkonsep "keseluruhan-bagian" dan "pemahamanpenjelasan".

Bisa disimpulkan bahwa ruang artistik terbangun dari beberapa medan semantis yang berupa elemen-elemen yang berhubungan satu sama lain dalam bentuk oposisi berpasangan, baik secara vertikal maupun secara horisontal Faruk [5]. Teknik oposisi biner yang diterapkan oleh Goldmann menjembatani penelitian teks, tidak hanya menilik pada struktur intern teks tersebut pun menjangkau faktor sosial. Plot adalah serangkaian peristiwa yang saling berhubungan satu sama lain dalam kerangka usaha penerobosan terhadap medan-medan semantik yang membangun struktur ruang artistik di atas Faruk [5]. Persona adalah representasi fungsi-fungsi abstrak, baik fungsi agen yang menjadi penerobos medan-medan semantis, maupun perintang yang mencoba mempertahankannya Faruk [5].

Adanya teori mengenai struktur ruang artistik ini guna membangun oposisi berpasangan yang ada dalam novel. Melalui struktur ruang artistik inilah maka dapat secara hierarki menjadi 
medan-medan semantis. Dengan diketahui medan-medan semantis tersebut dapat diungkap ideologi pengarang dalam sebuah karya sastra.

\section{METODE PENELITIAN}

Penelitian ini menggunakan pendekatan teoretis dan pendekatan metodologis. Pendekatan metodologis dalam penelitian ini mencakupi pendekatan deskriptif kualitatif. Menurut Sudaryanto [6], istilah deskriptif menyarankan bahwa penelitian yang dilakukan semata-mata hanya berdasarkan fakta yang ada atau fenomena yang memang secara empiris hidup pada penutur-penuturnya, sehingga yang dihasilkan atau yang dicatat berupa perian bahasa yang biasa dikatakan sifatnya seperti potret: paparan seperti apa adanya. Sejalan dengan hal tersebut pendekatan teoretis yang digunakan yaitu pendekatan ekspresif Abrams. "This way of thinking, in which the artist himself become the major element generating both the artistic product and the criteria by whic it is to be judge, I shall call the expressive theory of art"Abrams [7]. Teori yang digunakan menganalisis yaitu teori strukturalisme genetik Lucien Goldmann. Penggunaan kedua pendekatan ini dimaksudkan agar ditemukan struktur sosial yang melatarbelakangi karya tersebut serta relevansinya dengan kehidupan pengarang.

Wujud data dalam penelitian ini adalah penggalan teks yang berupa kata, frasa, kalimat, dan paragraf dalam trilogi Negeri 5 Menara karya Ahmad Fuadi yang diduga berisi pandangan dunia humanisme religius. Sumber data dalam penelitian ini adalah trilogi novel karya Ahmad Fuadi yakni Negeri 5 Menara, Ranah 3 Warna, dan Rantau 1 Muara. Selain penggalan dialog pada novel, sumber data yang lain adalah santri dan alumni santri pesantren Gontor Jawa Timur.

Teknik pengumpulan data dalam penelitian ini dilakukan dengan teknik pembacaan secara heuristik dan hermeneutik. Heuristik yakni pembacaan yang didasarkan atas kaidah kebahasaan. Teknik heuristik berguna untuk menjaring data fisik yang baik yang berkiatan dengan faktor kebahasaan maupun aspek pembentuk karya sastra. Pembacaan hermeneutik lebih fokus terhadap makna yang timbul pada karya sastra. Pencatatan setelahnya dilakukan dengan memilah-milah data yang valid dan menyeleksi data kurang valid.

Pada penelitian ini, digunakan uji validitas internal dan uji obyektivitas. Uji validitas internal (credibility) dilaksanakan untuk memenuhi nilai kebenaran dari data dan informasi yang dikumpulkan. Dengan kata lain, hasil penelitian harus dapat dipercaya oleh semua pembaca secara kritis. Kriteria ini berfungsi untuk melakukan inquiry sedemikian rupa sehingga kepercayaan penemuannya dapat dicapai.

Metode analisis data yang digunakan dalam strukturalisme genetik adalah metode dialektik. Metode dialektik mengutamakan makna yang koheren. Prinsip dasar metode dialektik adalah adanya pengetahuan mengenai fakta-fakta kemanusiaan akan tetap abstrak apabila tidak dibuat konkret dengan mengintregasikan ke dalam totalitas. Sehubungan dengan itu, metode dialektik mengembangkan dua pasangan konsep, yaitu " keseluruhan-bagian" dan " pemahamanpenjelasan" Faruk [4] .

Penelitian ini menggunakan teknik informal dalam penyajian data. Penerapan teknik informal dalam penyajian analisis yang direalisasikan dalam penggunaan kata, kalimat, serta istilah teknis untuk merumuskan dan menerangkan setiap permasalahan penelitian.

\section{HASIL DAN PEMBAHASAN}

Hasil penelitian struktur ruang artistik dari Negeri 5 Menara. Pertama, struktur teks Negeri 5 Menara berpusat pada tokoh hero yang bernama Alif Fikri. Keberadaan Alif sebagai tokoh hero tidak akan terpisahkan dengan tokoh yang lain karena menggambarkan hubungan timbal balik yang saling mempengaruhi karakter satu sama lain. Relasi tokoh hero ini berlangsung ketika dia hidup di pesantren sampai dia belajar diluar negeri. Relasi-relasi itulah yang kemudian bisa disebut sebagai unsur yang membangun keutuhan struktur Negeri 5 Menara. Pertama, relasi cinta dan persahabatan. Cinta dan persahabatan merupakan dua hal yang saling berkait dalam kehidupan manusia. Begitu pula dengan kehidupan dalam novel Negeri 5 Menara, Alif sebagai tokoh hero memiliki hubungan dengan kedua hal tersebut. Pada novel pertama, yaitu Negeri 5 
Menara, Sahibul menara merupakan sebutan bagi sahabat-sahabat Alif semasa menjalani pendidikan di pesantren. Personil sahibul menara yaitu Raja, Said, Dulmajid, Atang, dan Baso. Alif dan para sahabatnya itu mengukir mimpi di bawah menara masjid sembari menunggu adzan maghrib. Bukan hanya dengan sahibul menara, sebelumnya Alif juga memiliki sahabat sekaligus lawan sejak kecil yang bernama Randai. Persahabatan mereka makin renggang setelah saling berebut cinta Raisa, seorang gadis cantik kawan kuliah semasa di Bandung.

Kedua, relasi orang tua dan anak. Orang tua Alif yang berprofesi sebagai guru, menjadikan Alif sebagai sosok seorang yang sangat berbakti kepada orang tua. Hal ini dibuktikan setelah kelulusan Alif dari Madrasah Tsanawiyah atau setingkat dengan SMP, Alif dihadapkan dengan pilihan yang sangat sulit. Orang tua menginginkan Alif untuk memperdalam ilmu agama di pesantren, sedangkan Alif sendiri menginginkan untuk melanjutkan sekolah di sebuah SMA. Meski dengan setengah hati, Alif tetap mengikuti apa yang telah menjadi impian orang tuanya, yaitu belajar agama di pesantren. Bermula dari keputusan setengah hati itu, akhirnya Alif mampu menemukan jati diri dan juga ilmu berlimpah selama di pesantren. Bahkan untuk mengarungi samudra kehidupan, Alif selalu memegang teguh nasihat-nasihat kyai dan ustadz selama di pesantren. Mantra man jadda wajada adalah kunci hidup yang pernah dia dapatkan di pesantren. Dan dengan mantra tersebut, Alif mampu menjalani dan menakhlukkan berbagai macam cobaan dalam hidup.

Ketiga, relasi santri dengan ustadz. Relasi ustadz dan santri sangat tampak pada novel pertama yaitu Negeri 5 Menara. Selama di pesantren, hubungan antara ustadz dan santri sangat intens. Relasi Alif sebagai santri dan Kyai Rais sebagai pengasuh pesantren, Kyai Rais selalu memberikan nasihat-nasihat yang sangat berguna bagi santri. Salah satu nasihat yang senantdiasa menggema ditelinga santri adalah man jadda wajada, siapa yang bersungguh-sungguh pasti akan sukses.

Dalam struktur teks Negeri 5 Menara, terdapat medan-medan semantis berupa oposisi berpasangan yang menghadirkan dua hal saling bertentangan, namun saling melengkapi sehingga menimbulkan keseimbangan dan juga konflik. Medan-medan semantis ini merupakan varian yang mengarah kepada konstruksi untuk memperkuat eksistensi tokoh Alif sebagai tokoh yang mengekspresikan nilai-nilai humanisme religius. Pertama, oposisi kaya dan miskin. Dalam trilogi Negeri 5 Menara medan semantis yang berupa kaya dan miskin merupakan personifikasi yang mempertentangkan kehidupan Alif dengan Randai. Ketika kuliah di Bandung, Alif sering meminjam komputer milik Randai, sampai pada suatu ketika komputer tiba-tiba ruak dan Randai sangat murka kepada Alif. Saat itulah sangat tampak oposisi antara kaya dan miskin. Adanya oposisi antara kaya dan miskin ini menegaskan pergulatan Alif menghadapi kehidupannya ditengah keberadaan Randai. Keadaan miskin yang dialami oleh Alif tidak menjadikannya kehilangan martabat sebagai manusia. Dengan itulah Alif membuktikan eksistensi dirinya.

Kedua, oposisi kota dan desa. Medan semantis yang berupa oposisi kota dengan desa merepresentasikan dua hal yang sangat berbeda. Kota adalah representasi kehidupan modern dan juga mewakili kesan individualisme, sementara desa merupakan representasi dari kehidupan tradisional yang berlatar kemiskinan namun masih dengan keguyuban dan semangat kekeluargaan. Representasi kehidupan kota diwakili oleh kehidupan Alif semasa kuliah di Bandung, sedangkan kehidupan desa direpresentasikan ketika Alif hidup di pesantren. Ketiga, oposisi kehisupan dunia dan akhirat. Medan semantis berupa oposisi secara dunia dengan akhirat merupakan medan semantis yang penting dalam Negeri 5 Menara. Medan semantis ini dipersonifikasi melalui pertentangan dunia dengan akhirat. Alif, sebagai tokoh hero dengan segala kemampuannya berusaha untuk menyeimbangkan kehidupan akhirat dan kehidupan dunia. Segala hal yang dipertentangkan antara dunia dan akhirat mencoba diseimbangkan oleh tokoh utama. Setelah enam tahun tinggal di pesantren dan hari-harinya disibukkan dengan kegdiatan pesantren, pada akhirnya Alif tetap melanjutkan pendidikannya ke perguruan tinggi. Dengan diterimanya Alif sebagai mahasiswa salah satu perguruan tinggi di Bandung, dia harus hidup mandiri. Setiap hari, dia berpacu dengan waktu untuk mencukupi hidup, apalagi setelah kepergdian ayahnya. Ditengah kesibukan tersebut, Alif tidak pernah lalai untuk menjalankan ibadah kepada Tuhan, sebagai wujud pengabdian sebagai makhluk ciptaan Tuhan. 
Keempat, oposisi laki-laki dan perempuan. Medan semantis yang selanjutnya yaitu oposisi antara laki-laki dan perempuan. Dalam Negeri 5 Menara, oposisi laki-laki dan perempuan ditempatkan secara sejajar dan saling melengkapi. Bukan dalam posisi ordinat dan subordinat. Laki-laki mendukung keberadaan perempuan dan begitu pula sebaliknya. Dalam novel ini, lakilaki digambarkan sebagai laki-laki yang menganggap perempuan sebagai mitra kerja. Perempuan digambarkan sebagai seorang yang bebas menentukan pilihan dalam hidupnya.

Struktur teks dalam Negeri 5 Menara, selain struktur ruang artistik juga dikaji latar dalam trilogi tersebut. Latar dalam Negeri 5 Menara ini meliput latar ruang, waktu, dan sosial. Latar ruang, meliputi tempat-tempat yang yang menjadi fokus pada tiap novel. Dalam novel pertama, pesantren madani adalah tempat yang menjadi fokus kegiatan Alif.

Latar waktu menggambarkan peristiwa flashback kehidupan tokoh Alif yang berlangsung dalam rentang waktu lebih dari sepuluh tahunan, dengan acuan empat tahun di pesantren kemudian dilanjutkan dengan kuliah di UNPAD empat tahun, lulus di era reformasi. Persoalan yang dikisahkan dalam tiap novel yaitu prareformasi, reformasi, dan pascareformasi. Latar sosial berkaitan dengan perilaku kehidupan sosial pesantren, mahasiswa, dan karyawan pada sosial budaya masyarakat era tersebut.

\section{Struktur Sosial Yang Melatarbelakangi Lahirnya Karya}

Salah satu unsur genetik sebuah karya sastra adalah struktur sosial. Hal ini karena karya sastra merupakan ekspresi sosial budaya suatu masyarakat pada kurun waktu tertentu. Pandangan dunia humanisme religius adalah respon pengarang terhadap situasi sosial yang ada disekeliling kehidupannya. Pandangan dunia humanisme religius merupakan ideologi yang diperjuangan Ahmad Fuadi beserta kelompok sosialnya yang berusaha mengarahkan kehidupan mereka sebagai manusia yang bermartabat, berakhlaq dan beradab.

Pertama, kondisi sosial kesastraan islami tahun 2000an. Kesastraan islami mengalami perkembangan yang sangat pesat pada tahun 2000an. Munculnya nama-nama seperti Habiburrahman, Asma Nadia dan juga Andrea Hirata menambah khasanah kekayaan kesastraan islami yang kini semakin diminati oleh para pembaca. Sastrawan angkatan 2000an ini merefleksikan keadaan sosial politik yang telah terjadi pada saat jatuhnya rezim orde baru. Kepenulisan novel mengalami kebangkitan sangat pesat dengan tema-tema religius yang sangat kental. Ketika geliat pasar sastra islami begitu berkembang, penerbit-penerbit mulai menyajikan fiksi-fiksi berbau islami. Misalnya Republika yang menerbitkan karya-karya Habiburrahman dan Gramedia yang menerbitkan karya Ahmad Fuadi. Demikianlah maraknya karya sastra islami yang menjadi rangkaian sejarah sastra Indonesia kala itu, yang akhirnya melahirkan salah satu karya yaitu trilogi Negeri 5 Menara.

Kedua, struktur sosial lingkungan pengarang. Sebuah pandangan dunia seorang pengarang dalam menciptakan karya sastra, tidak bisa dilepaskan dari pengalaman hidup yang telah dilaluinya, baik secara pribadi maupun sebagai anggota kelompok sosial tertentu. Biografi seorang pengarang dapat menjelaskan dan menerangkan proses penciptaan karya sastra. Ahmad Fuadi lahir di Bayur Maninjau, Sumatera Barat 30 Desember 1972. Masa pendidikan SD dan SMP Ahmad Fuadi dijalani di tanah kelahirannya yaitu Maninjau, Agam, Sumatra Barat. Ahmad Fuadi memulai pendidikan menengah di KMI Pondok Modern Darussalam Gontor, Ponorogo karena keinginan sang ibu. Di pondok Gontor, dia mendapat pesan dan nasehat dari guru-guru atau ustad-ustadnya "man jadda wajada", yang artinya "barang siapa yang bersungguh-sungguh pasti akan menemui kesuksesan", serta ada sebuah kata-kata lagi yang selalu dia ingat bahwa "orang yang paling baik di antaramu adalah orang yang paling banyak manfaat." Akhirnya pesan-pesan tersebut yang menjadi prinsip yang selalu dipegang dalam hidup.

Ketiga, kondisi sosial budaya masyarakat dilingkungan pengarang. Berhubungan dengan konteks sosial budaya yang konkret dari masyarakat tempat lahirnya trilogi Negeri 5 Menara, gambaran tersebut dapat dikorelasikan dengan keadaan sosial budaya di pesantren era 90an, kondisi kota Bandung dan Jakarta masa Reformasi, serta kondisi Amerika tahun 2000an. Pengarang adalah seorang yang dilahirkan dengan latar belakang keislaman yang kuat. Kakeknya 
adalah salah satu ulama besar dikampungnya. Setelah merampungkan sekolah di madrasah Tsanawiyah, setingkat dengan SMP dia harus pergi merantau ke Gontor sebuah pesantren yang membawanya mewujudkan cita-cita. Lingkungan pesantren yang selama ini dianggap kumuh dan kolot terkikis sudah dengan hadirnya pesantren Gontor. Selama di pesantren, banyak hal yang telah dipelajari oleh pengarang, tentang keikhlasan, kemandirian dan kebersamaan.

\section{SIMPULAN}

Pada penelitian ini telah diuraikan bahwa untuk menemukan dan memahami trilogi novel Negeri 5 Menara secara menyeluruh perlu dipahami bahwa novel-novel tersebut memiliki kesatuan-kesatuan yang utuh. Dalam arti bahwa trilogi novel ini tidak hanya dipahami dari struktur naratif saja, tetapi perlu dihubungkan dengan struktur sosial masyarakat tempat novel tersebut diciptakan. Antara struktur naratif dan struktur sosial tesebut, dimediasi oleh pandangan dunia (worldview).

Berdasarkan hasil penelitian dan pembahasan dapat disimpulkan sebagai berikut. (1) Struktur teks novel Negeri 5 Menara meliputi ruang artistik yang terbangun dari beberapa medan semantis berupa elemen-elemen yang berelasi antara satu dengan yang lain dan adanya oposisi berpasangan. Relasi yang terbangun dalam trilogi novel Negeri 5 Menara yaitu relasi tokoh hero dengan tokoh lain yang meliputi relasi cinta dan persahabatan, relasi orang tua dan anak, relasi santri dengan ustadz. Medan-medan semantis dalam trilogi novel Negeri 5 Menara berupa oposisi berpasangan yang meliputi, oposisi kaya dan miskin, oposisi kota dan desa, oposisi kehidupan dunia dan akhirat, oposisi laki-laki dan perempuan. Struktur teks yang terakhir yaitu latar, meliputi latar ruang, latar waktu, dan latar sosial. (2) Struktur sosial yang melatarbelakangi lahirnya trilogi novel negeri 5 menara yaitu (1) kondisi sosial kesastraan islami tahun 2000an, (2) struktur sosial pengarang yang berkaitan dengan latar belakang pendidikan dan latar belakang keluarga, (3) kondisi sosial dan budaya masyarakat dilingkungan pengarang.

\section{REFERENCE}

[1] Supriyanto, Teguh., 2008, Teks dan Ideologi: Studi Sastra Populer Cerita Silat, Semarang: Unnes Press.

[2] Mangunwijaya, YB., 1992, Sastra dan Religiusitas, Yogyakarta: Penerbit Kanisius.

[3] Wellek, Rene dan Warren, Austin., 1993, Teori Kesusastraan, Jakarta: PT Gramedia Pustaka Utama. (Terjemahan Melani Budianta).

[4] Faruk, 2012, Metode Penelitian Sastra: Sebuah Penjelajahan Awal, Yogyakarta: Pustaka Pelajar.

[5] Faruk, 2012, Novel Indonesia, Kolonialisme dan Ideologi Emansipatoris, Yogyakarta: Penerbit Ombak.

[6] Sudaryanto, 1993, Metode dan Aneka Teknik Analisis Bahasa, Yogyakarta: Gadjah Mada University Press.

[7] Abrams, M.H., 1999, A Glosary of Literary Terms, New York: Company, inc.,Publishers. [Online] Available:

https://mthoyibi.files.wordpress.com/2011/05/a-glossary-of-literary-terms-7th-ed_m-habrams-1999.pdf

[8] Tenshak, Juliet., 2014, "History, Culture, and Tradition in Helon Habila's Measuring Time". International Journal English Language and Translation Studies. [Online] Available:https://www.academia.edu/8464264/History_Culture_and_Tradition_in_Helon _Habila_s_Measuring_Time 
[9] Subha, M., 2014, "Indian Postmodern English Novels: A Diachronic Survey". International Journal of English Language and Translation Studies. [online] Avaible : https://www.researchgate.net/publication/334318305_International_Journal_of_English_ Language_Translation_Studies_Journal_homepage_httpwwweltsjournalorg_Indian_Post modern English Novels A Diachronic Survey

[10] Farhat, Emdellah O.M., 2014, "Gender, Power, Politeness, and Women in The Arab Society". Internatonal Journal English Language and Translation Studies. Vol. 1. [Online]

Available:https://www.academia.edu/3764271/Gender Power Politeness and Women i n the Arab Society

[11] Hawa, Masnuatul, 2012, "Novel Ranah 3 Warna Karya Ahmad Fuadi: Analisis Psikologi dan Nilai Pendidikan". Tesis. Surakarta: Universitas Sebelas Maret Surakarta. [online] Available: https://digilib.uns.ac.id/dokumen/detail/27656/Novel-Ranah-3-Warna-Karya$\underline{\text { Ahmad-Fuadi-Analisis-Psikologi-Sastra-dan-Nilai-Pendidikan }}$

[12] Indrayanti, Tri, 2012, "Kajian Intertekstual dan Nilai Pendidikan Novel Sang Pemimpi Karya Andrea Hirata dan Novel Ranah 3 Warna Karya Ahmad Fuadi". Tesis. Surakarta: Universitas Sebelas Maret Surakarta. [Online] Available :https://digilib.uns.ac.id/dokumen/detail/29227/Kajian-Intertekstual-Dan-NilaiPendidikan-Novel-Sang-Pemimpi-Karya-Andrea-Hirata-Dan-Novel-Ranah-3-WarnaKarya-Ahmad-Fuadi

[13] Irawan, Benny, 2014, "Aspek Motivasi Pada Novel Negeri 5 Menara Karya Ahmad Fuadi dan Novel Sepatu Dahlan Karya Khrisna Pabichara: Kajian Intertekstual dan Implementasinya sebagai Bahan Ajar Sastra di SMA". Tesis. Surakarta: Universitas Muhammadiyah Surakarta.

http://v2.eprints.ums.ac.id/archive/etd/31479

[Online]

Available: 